\title{
Chapter 5: Japan: Obstacles, Lessons and Future
}

\section{MASAMICHI MINEHATA AND NARIYOSHI SHINOMIYA}

Japan has a clear rationale to discuss the introduction of ethical education for life scientists regarding its dual-use dimensions. ${ }^{1}$ This partly derives from the size of its life-science industry and from the actual threats posed by the misuse of science. Japan has been one of the leading global marketplaces of the life-science industry. ${ }^{2}$ This indicates that a large number of life scientists are practising cutting-edge research in Japan. Importantly, some of them have misused their knowledge in the form of biocrimes and bioterrorism. One of the most prominent cases of such misuse was that of the religious group Aum Shinrikyo. By recruiting scientists from top academic institutions, the group was able to conduct sarin attacks on the Tokyo subway in 1995. The group also attempted several biological attacks using botulinum toxin and anthrax from 1990 to $1995 .^{3}$ Therefore, enhancing ethical awareness among scientists is of critical importance in extending their moral responsibility to do no harm and minimise any potential damage to humans, animals and plants.

Although attempts to define 'biosecurity' are not straightforward, ${ }^{4}$ in this chapter it is conceptualised as taking both 'preventative and responsive measures, in a multifaceted manner, to mitigate the multidimensional threat

\footnotetext{
1 In this chapter, dual-use refers to the possibility whereby peacefully developed scientific research can be applied for malign purposes, such as biowarfare and bioterrorism.

2 See Chapter 3 of National Research Council 2006, Globalization, biosecurity and the future of the life sciences, Washington, DC: National Academies Press.

3 Sugishima, M. 2003, 'Biocrimes in Japan', in Sugishima, M. (ed.), A comprehensive study on bioterrorism, Legal Research Institute Monograph, Japan: Asahi University; Wheelis, M. and Sugishima, M. 2006, 'Terrorist use of biological weapons', in Wheelis. M., Rozsa, L. and Dando, M. R. (eds), Deadly cultures: Biological weapons since1945, MA: Harvard University Press; Takahashi, H., Keim, P., Kaufmann, A. F., Keys, C., Smith, K. L., Taniguchi, K., Inouye, S. and Kurata, T. 2004, 'Historical review: Bacillus anthracis incident, Kameido, Tokyo, 1993', Emerging Infectious Diseases, vol. 1(1), pp. 117-20.

4 The term 'biosecurity' has been defined in different concepts in different social and linguistic backgrounds in different countries. See Sunshine Project 2003, 'Biosafety, biosecurity, and biological weapons', background paper on three agreements on biotechnology, health, and the environment, and their potential contribution to biological weapons control, October 2003, available: http://www.natwiss.de/publikationen/Biosafety_ and_Biosecurity.pdf [viewed 17 January 2010]; Fidler, D. and Gostin, L.L. 2007, Biosecurity in the global age: Biological weapons, public health, and the rule of law, CA: Stanford University Press.
} 
posed by bioterrorism, biowarfare, and the potential advertent or inadvertent misuse of the life sciences' ${ }^{5}$ This is a broader concept than that often given to 'laboratory biosecurity', ${ }^{6}$ although in Japan at this time the latter is generally understood as 'biosecurity'.$^{7}$ Therefore, in this chapter biosecurity education is also widely envisaged as a process to better inform understanding of how the possible misuse of the life sciences can be prevented. It includes themes such as, inter alia, the history of state-level offensive biological-warfare programmes and biological terrorism; the history and evolution of the international prohibition regimes and their national implementation; ${ }^{8}$ dual-use risks and ethical responsibilities of life scientists; and building an effective set of preventative policies to ensure benign development of the life sciences.

In order to improve biosecurity education in Japan, it is necessary to understand the existing provisions regarding dual-use issues and learn lessons from the implementation of such teaching. This is useful for accumulating knowledge in biosecurity education to share with other countries. To achieve this purpose, this chapter will give a brief overview of Japan's stance towards international efforts to mitigate the threat posed by misuse of the life sciences. Secondly, the chapter shifts its focus to a domestic context by providing the survey results on biosecurity educational provisions in 197 university-level life-science degree courses. Thirdly, biosecurity education at Japan's National Defense Medical College (NDMC) will be used as an example of the introduction of such education. Finally, the way forward for the education of life scientists in Japan will be envisaged.

\footnotetext{
5 Minehata, M. and Shinomiya, N. 2009, Biosecurity education: enhancing ethics, securing life and promoting science: dual use education in life-science degree courses at universities in Japan, Saitama and Bradford: National Defense Medical College and the University of Bradford, available: http://www.dual-usebioethics. net/ [viewed 17 January 2010]. There have been efforts to conceptualise a multifaceted approach comprising several practical measures through what is termed the Web of Prevention (WoP). For the conceptual evolution of the WoP in literature, see Feaks, D., Rappert, B. and McLeish, C. 2007, 'Introduction: A web of prevention', in Rappert, B. and McLeish, C. (eds), A web of prevention: Biological weapons, life science and the governance of research, London: Earthscan.

6 The World Health Organisation definition of laboratory biosecurity refers to 'institutional and personal security measures designed to prevent the loss, theft, misuse, diversion or intentional release of pathogens and toxins'. See World Health Organisation 2004, Laboratory Biosafety Manual, Geneva: WHO, p. 47.

7 Furukawa, K. 2009, 'Dealing with the dual-use aspects of life science activities in Japan', in Rappert, B. and Gould, C. (eds), Biosecurity: Origins, transformations and practices, Hampshire: Palgrave Macmillan.

8 Such as BTWC of 1972, Chemical Weapons Convention of 1993 or Geneva Protocol of 1925.
} 


\section{Japan's Stance on the Dual-Use Issue: The International Context}

Amongst other calls to the international community, ${ }^{9}$ States Parties of the Biological and Toxin Weapons Convention (BTWC) have in recent years conducted in-depth discussions on, for example, national measures to implement laboratory biosecurity (2003), the adoption of codes of conduct for scientists (2005) and the promotion of education on dual-use issues (2008). ${ }^{10}$ As a result of these processes, Japan has been constantly considering its own views.

In the discussion on codes of conduct for life scientists, in particular, Japan addressed some key elements of awareness-raising among scientists. It explained that the lack of awareness among scientists was not to be taken as a sign of 'the immorality of scientists'; rather, 'the misconduct and failures of scientists are not caused by a lack of ethics but rather by ignorance'. ${ }^{11}$ Therefore, the objective of the codes was the reduction of 'the risk of sciences causing negative effects on human beings and society through establishing specific rules that scientists should abide by'. Japan proposed to 'ensure scientists realize the risks of biological agents they handle, the possibility their research results may be abused and the effects of them actually being abused'. Furthermore, it was acknowledged that scientists themselves should be the 'core people' to formulate such codes, although involvement by other people concerned is also necessary. ${ }^{12}$ At the same meeting the Japan Bioindustry Association (JBA) also illustrated its mandatory professional rules and guidelines, stating that such standards were important in ensuring both 'corporate compliance' and social responsibility of the industrial sector. ${ }^{13}$

\footnotetext{
9 The necessity of education wastouched upon in the Statement on Biosecurity by the InterAcademy Panel, which was endorsed by the national science academies of more than 60 states in 2005; see InterAcademy Panel 2005 Statement on Biosecurity, available: http://www.interacademies.net/?id=4909[viewed 17 December 2008]; World Health Organisation 2007, Scientific working group on life science research and global health security: Report of the first meeting, Geneva: WHO.

10 United Nations 2002, Final Document of the Fifth Review Conference of the States Parties to the Convention on the Prohibition of the Development, Production and Stockpiling of Bacteriological (Biological) and Toxin Weapons and on Their Destruction, BWC/CONF.V/17, Geneva: UN, available: http://www.opbw.org/ [viewed 17 January 2010]; United Nations (2006) Final Document of the Sixth Review Conference of the States Parties to the Convention on the Prohibition of the Development, Production and Stockpiling of Bacteriological (Biological) and Toxin Weapons and on Their Destruction, BWC/CONF.VI/6, Geneva: UN, available: http://www.opbw.org/ [viewed 17 January 2010].

11 Japan 2005a, Codes of conduct for scientists: Discussions in Japan on the issue, BWC/MSP2005/MX/WP.21, Geneva: UN, available: http://www.opbw.org/ [viewed 17 January 2010], p. 4.

12 .Ibid. p. 4.

13 Japan 2005b, Codes of conduct for scientists: A view from analysis of the bioindustrial sectors in Japan, BWC/MSP2005/MX/WP.22, Geneva: UN, available: http://www.opbw.org/ [viewed 17 January 2010], p. 3.
} 


\section{Lack of Awareness}

Despite the amount of international attention given to awareness-raising among scientists, specific provisions for biosecurity education are not prevalent in many countries. This deficiency has been elaborated in the national papers of States Parties to the meetings of the BTWC, particularly by Australia, ${ }^{14}$ the UK and the Netherlands. ${ }^{15}$ Experts within the non-governmental community have also reached similar conclusions. For example, after conducting some 90 interactive seminars with more than 2500 life scientists in 13 different countries, Dando and Rappert concluded that there was a pervasive lack of awareness amongst individual scientists of the dual-use aspects of their research. ${ }^{16}$ This was further supported by the survey on biosecurity education in European universities by Giulio Mancini and James Revill, demonstrating the deficiency of education in dual-use issues for life scientists. ${ }^{17}$

At a BTWC meeting in 2008, Japan acknowledged that 'the development of educational programmes at the government level has not seen great progress' ${ }^{18}$ One explanation for this is that, despite a growing attention to biosecurity issues and the development of some related regulations, human and financial resources to institutionalise and coordinate preventative measures to minimise dual-use risks in the life sciences are still limited amongst relevant ministries and scientific communities. ${ }^{19}$ Thus it could be expected that biosecurity-education provisions have not been prevalent in higher-education institutions in Japan.

14 Australia 2005, Raising awareness: Approaches and opportunities for outreach, BWC/MSP/2005/MX/ WP.29, Geneva: UN, available: http://www.opbw.org/ [viewed 17 January 2010].

15 UK and Netherlands 2005, Oversight, education and awareness-raising: Report of a UK seminar, BWC/ MSP/2008/MX/WP.10, Geneva: UN, available: http://www.opbw.org/ [viewed 17 January 2010].

16 Dando, M. R. and Rappert, B. 2005, 'Codes of conduct for the life sciences: Some insights from UK academia', Bradford Briefing Papers, no. 16, available: http://www.brad.ac.uk/acad/sbtwc/briefing/ BP_16_2ndseries.pdf [viewed 17 January 2010]; Rappert, B., Chevrier, M.I. and Dando, M.R. 2006, 'In-depth implementation of the BWC: Education and outreach', Bradford Review Conference Papers, no. 18, available: http://www.brad.ac.uk/acad/sbtwc/briefing/RCP_18.pdf [viewed 17 January 2010]; Rappert, B. (2009) Experimental secrets: International security, codes, and the future of research, New York: University Press of America.

17 The survey reported that only three out of 57 universities investigated in Europe offered specific biosecurity modules. See Mancini, G. and Revill, J. 2008, Fostering the biosecurity norm: Biosecurity education for the next generation of life scientists, Como and Bradford: Landau NetworkCentro Volta and the University of Bradford, available: http://www.centrovolta.it/landau/2008/11/07/ FosteringTheBiosecurityNormAnEducationalModuleForLifeSciencesStudents.aspx [viewed 17 January 2010]; Revill, J., Mancini, G., Minehata, M. and Shinomiya, N. 2009, ‘Biosecurity education: Surveys from Europe and Japan', Background paper for the international workshop on promoting education on dual-use issues in the life sciences, 16-18 November 2009, Warsaw, Poland: Polish Academy of Sciences, available: http://dels. nas.edu/bls/warsaw/background.shtml [viewed 18 January 2010].

18 in consultation with Australia, Canada, Republic of Korea, Switzerland, Norway and New Zealand2008, Oversight, education, awareness raising, and codes of conduct for preventing the misuse of bio-science and biotechnology, BWC/MSP2008/MX/WP.21, Geneva: UN, available: http://www.opbw.org/ [viewed 17 January 2010], p. 4.

19 Furukawa 2009, op. cit. 
If there has been little evidence of such instruction, it is worth investigating why these subjects have not been incorporated and how faculty members view the relevance of issues such as dual use, biosecurity and biosafety. It is important to identify what kinds of obstacles exist in order to implement such education. In other words, a focused investigation would be able to identify how faculty members recognise 'uncertainties, unknowns, and doubts' about education on dual-use issues, as illustrated in the introductory chapter of this book. By identifying these obstacles it will be possible to envisage effective future polices to help mitigate the current lack of awareness about dual-use issues.

\section{Survey on Biosecurity Education in Japan}

In this context, the NDMC in Japan and the University of Bradford in the UK, conducted a survey to analyse the current state of biosecurity education in Japan. ${ }^{20}$ The investigation looked at 197 life-science degree courses consisting of 98 undergraduate and 99 postgraduate curricula at 62 universities from 36 different prefectures/regions in Japan. Employing the same basic structure and methodology as the survey on biosecurity education in European universities, ${ }^{21}$ the study consisted of two data-collection stages. The first was an online investigation focusing on publicly available syllabi and other information from the websites of life-science degree courses. Specifically, this investigation looked for six possible indicators of biosecurity-education topics. The first three indicators were used to identify the 'presence of modules' on respective subjects within the existing curricula. Thus, the survey asked whether there was evidence of specific modules on 'biosecurity', 'biosafety'22 and 'bioethics'.

The remaining three indicators were used to identify the 'presence of references' to respective topics within existing modules, even though there are no particular modules on such topics. Thus, the survey asked whether there was evidence of specific references to the following topics within current curricula: dual-use issues; international arms-control or disarmament regimes; and ethical guidelines as well as codes of conduct. The second stage was a follow-up questionnaire to clarify the findings of the online investigation.

\footnotetext{
20 Minehata and Shinomiya 2009, op. cit.

21 Revill 2008, op. cit.

22 In Japan the terms 'biosecurity' and 'biosafety' are used differently. Regarding the former, see note 5. Biosafety measures have been taken in laboratories by safely managing pathogens and toxins with a view to preventing accidental release of bioagents into the field and the exposure of people. Moreover, scientific research on genetic engineering has been taking place internationally based on the Cartagena Protocol on Biosafety to the Convention on Biological Diversity adopted in 2000. Japan introduced the Law Concerning the Conservation and Sustainable Use of Biological Diversity through Regulations on the Use of Living Modified Organisms, which came into force in 2004.
} 
The available information was organised into four categories, as follows:

Exist: refers to data where we can say with a degree of certainty that the required information was present

Not Exist: refers to data where we can say with a degree of certainty that the required information was not present

Unclear: refers to data where there is some information available but we cannot say with certainty whether the required information exists or not

Not Available: refers to data where there are significant constraints upon access to the required information.

\section{Survey Results}

Figure 1 shows that the survey identified three specific biosecurity modules and some other instances of biosecurity-specific teaching. Although there were only 18 cases of biosafety modules, biosafety education has been provided in many universities by means other than a single educational component. Bioethics modules were the most commonly found topic in this survey, with 138 examples. In a small number of cases these also dealt with dual-use issues. Some 34 universities included topics of relevance to dual-use issues without using this specific term. References to international prohibition regimes against biological and toxin weapons were also limited, with only 11 cases found. Finally, references to ethical guides or codes were fairly prevalent, with 94 cases largely included in bioethics modules. However, only a small number of ethical guides or codes addressed dual-use issues.

The survey questionnaire asked whether faculty members were familiar with the investigation topics. If they were not familiar with the terms of enquiry, it is very difficult to expect the presence of either modules or references. In view of this, the beginning of the questionnaire asked: 'Have you ever heard about the terms 'biosecurity', 'biosafety' and 'dual use'?' Figure 2 shows the extent of familiarity with these specific references as demonstrated by the questionnaire results. The terms 'biosecurity' and 'biosafety' were relatively well known to the respondents (with 21 positive recognitions). Although this survey broadly defined 'dual use' as referring to the possibility of a misuse of science for hostile purposes, in Japan the term more commonly refers to the possibility of military technology being applied for civilian purposes, and vice versa. ${ }^{23}$ Thus, the familiarity of respondents with the term within this survey could be expected to be low. Indeed, 17 respondents were not familiar with the reference. 


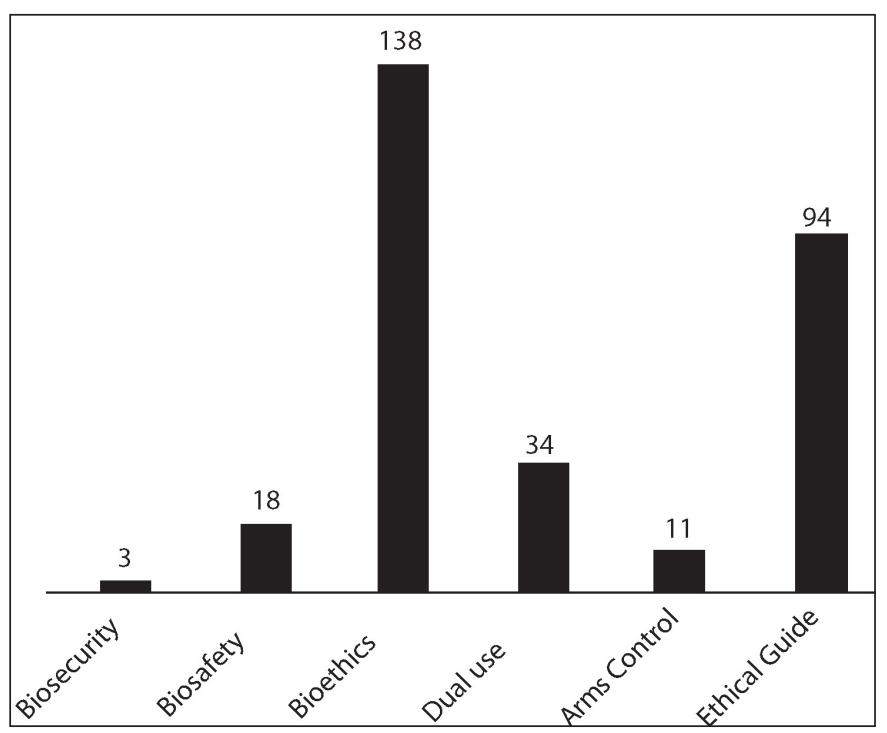

Figure 1: Implementation of Surveyed Topics in Japan

Specific modules on biosecurity, biosafety and reference to arms control have been less developed ( $n=3, n=17$, $n=10)$, whilst modules on bioethics and references to ethical guides were numerous $(\mathrm{n}=137, \mathrm{n}=94)$.

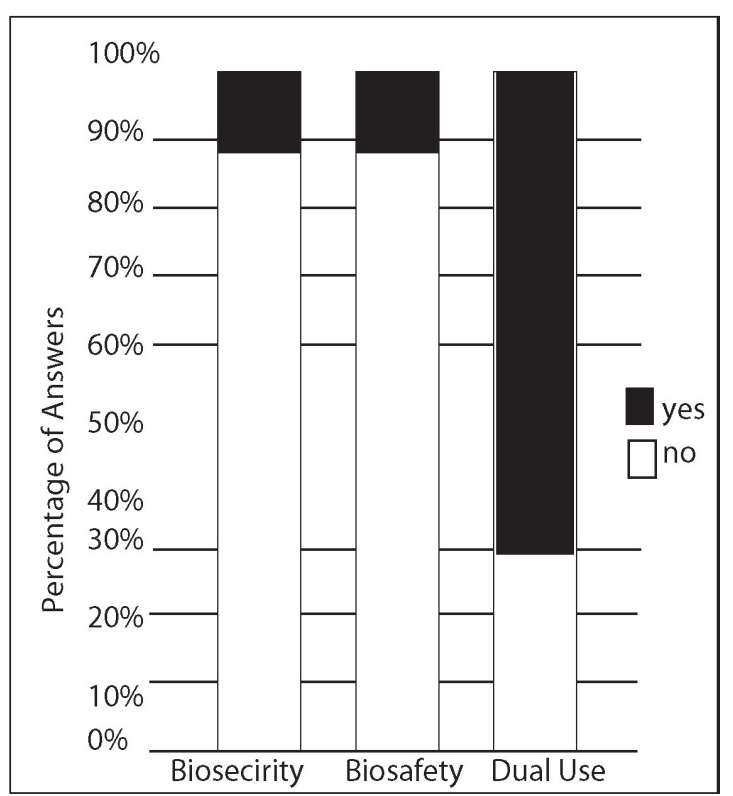

Figure 2: Level of Familiarity with the Terms

The majority were familiar with the terms biosecurity and biosafety (white, $n=21$ ), but not with dual use (black, $n=17$ ). 


\section{Biosecurity Modules}

Quantitatively, three cases of biosecurity module were discovered, and all of these were at postgraduate level (see Figure 3). These existing modules were primarily focused on public-health preparedness against the threat of the deliberate use of pathogens or accidental release of diseases. Thus, one module provides an educational course that considers biological risks vis-à-vis international public-health policy, mainly focusing on public-health responses to biological and chemical weapons; surveillance of infectious diseases in Japan; and issues related to international public-health policy and processes. Similarly, another module introduces risk-management policy in the public-health sphere in relation to biological and chemical terrorism.

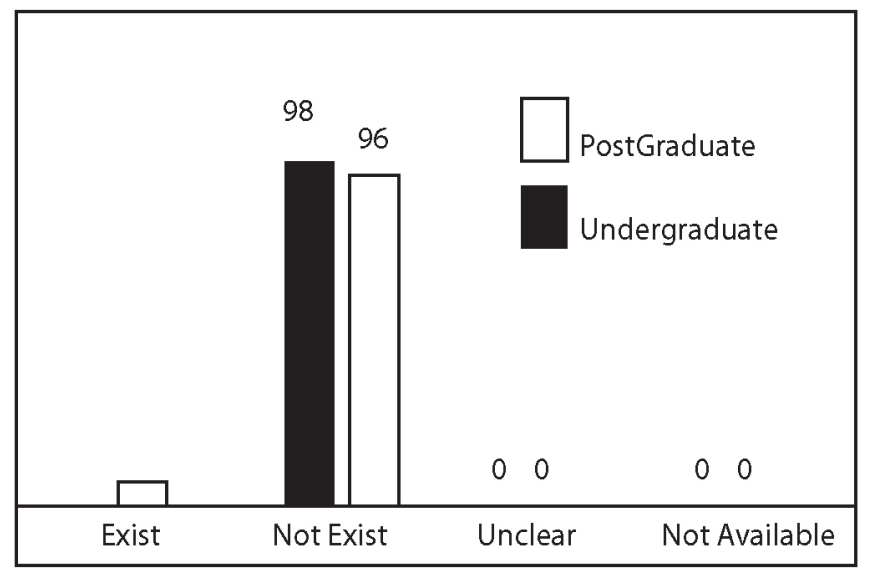

Figure 3: Number of Biosecurity Modules

Only three specific modules on biosecurity have been developed $(n=3)$ at postgraduate level.

Among the universities that had not conducted any biosecurity modules, some have been implementing education in this area on a more ad hoc basis by organising seminars/conferences or providing online educational facilities. There is a trend for such events and materials to focus on the following aspects: laboratory biosecurity and biosafety measures, national and local responses to bioterrorism, and emerging and re-emerging diseases. Amongst the examples identified is a medical department which has a 'Bio-Preparedness Wiki' providing an online and open information-exchange platform for users to both download and upload information to this website. ${ }^{24}$

24 Keio University 2009, Keio Bio-Preparedness Wiki, available: http://biopreparedness.jp/index. php?MEXTPJ_en [viewed 17 January 2010]. 


\section{Biosafety Modules}

In respect to the introduction of the national legislation to implement the Cartagena Protocol on Biosafety in 2004, universities have set up committees to inform university members and students about the characteristics and physical management of pathogens and relevant national regulations for the prevention of the spread of diseases. Some committees have both laboratory biosafety and biosecurity measures, and mandate their university to provide certain types of education for students. Moreover, there were already some biosafety measures that had been developed in Japan by the National Institute of Infectious Diseases (NIID) and encoded in the 'Biosafety in Microbiological and Biomedical Laboratories' guidelines. ${ }^{25}$

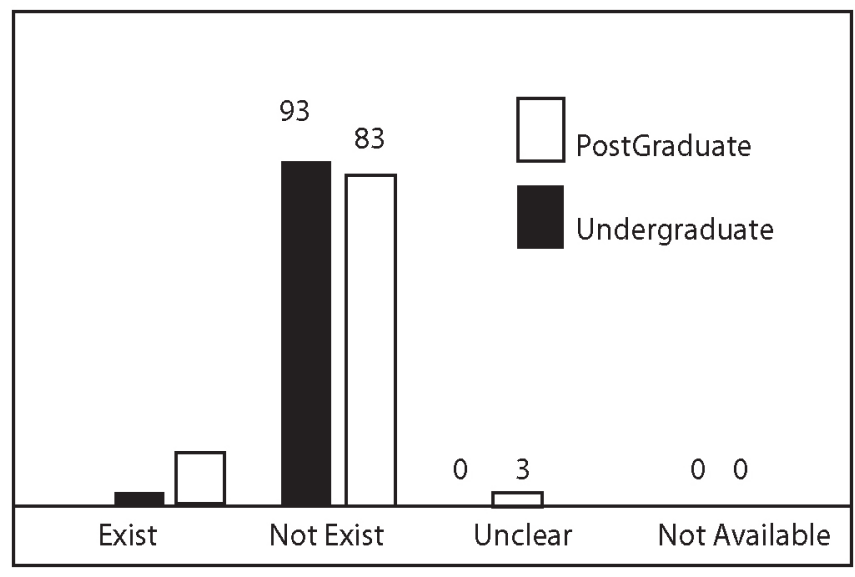

Figure 4: Number of Biosafety Modules

A small number of specific biosafety modules have been developed at undergraduate (black, $n=5$ ) and postgraduate levels (white, $n=13$ ).

However, as Figure 4 indicates, this does not mean universities are obliged to provide a specific module on biosafety for the purpose of educating students. Nonetheless, 18 cases of particular modules were identified, and more than twothirds were at postgraduate level. Although we found examples of modules using the term 'biosafety' in subject titles, more generally biosafety measures tend to be mentioned as part of other modules. Some of the biosafety processes are provided in relation to laboratory biosecurity systems to physically contain dangerous pathogens and toxins.

25 Japan 2005b, op. cit.p. 2. 


\section{Bioethics Modules}

Bioethics modules were found in 138 out of 197 courses in this survey (see Figure 5). Amongst other things, the main components included the history of medicine, the self-determination of patients, informed consent, transplants, gene therapy and counselling. These elements could overlap with ethical guidelines and codes of conduct for scientists such as the Declaration of Geneva of 1948, the Hippocratic Oath and the Declaration of Helsinki of 1964 for medical professionals. $^{26}$

Although the majority of bioethics modules were not framed in the context of dual-use issues, there were some that arguably considered them. For example, there was a module, Ethics in Human Experiments, which reviews the history of German, US, and Japanese human experiments since World War I and includes the Japanese bioweapons programme. Another module, Science Technology and Society, considers the conduct and dual-use ethics of scientists using nuclear science and nuclear weapons as examples.

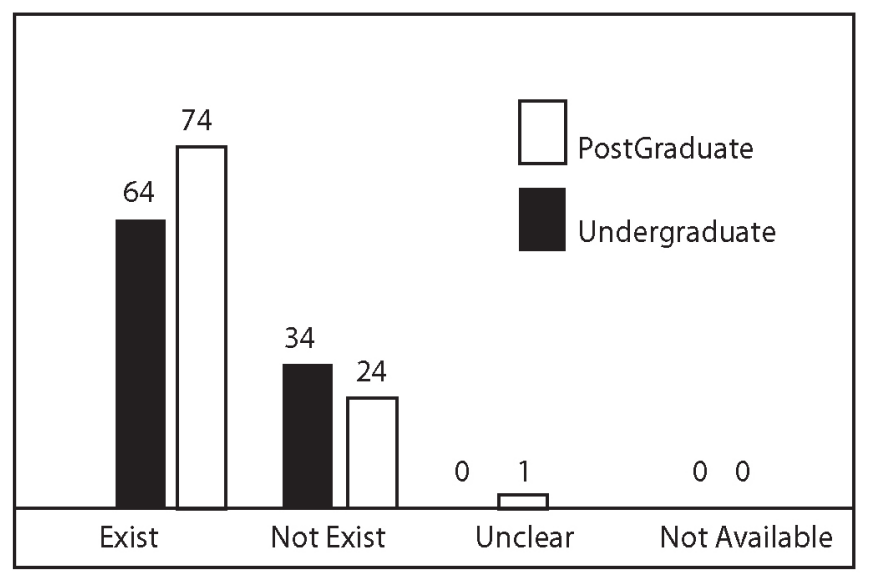

Figure 5: Number of Bioethics Modules Bioethics modules were prevalent at both undergraduate (black, $n=64$ ) and postgraduate levels (white, $n=74$ ).

A graduate school of science gives specific educational content on dual-use issues in the life sciences. A module, Introduction to Research Ethics, provides a specific lecture on Social Responsibility of Scientists: From a Perspective of National Security, including the issue of dual use and biosecurity. The school also provides a bioethics module, Bioethical Science, which considers security and social dangers derived from unpredictable risks in new life-science research. The research centre associated with the school offers seminars including

26 World Medical Association Declaration of Helsinki: Ethical principle for medical research involving human subjects,available: http://www.wma.net/en/30publications/10policies/b3/index.html [viewed 17 January 2010]. 
Promoting Research Ethics: From a Web to Practice in Preventing the Destructive Application of Science. This exhibits one of the most comprehensive approaches towards dual-use issues by indicating the necessity of multifaceted measures to deal with threats posed by the misuse of the life sciences, including biosecurity and biosafety measures. ${ }^{27}$

\section{Dual-Use References}

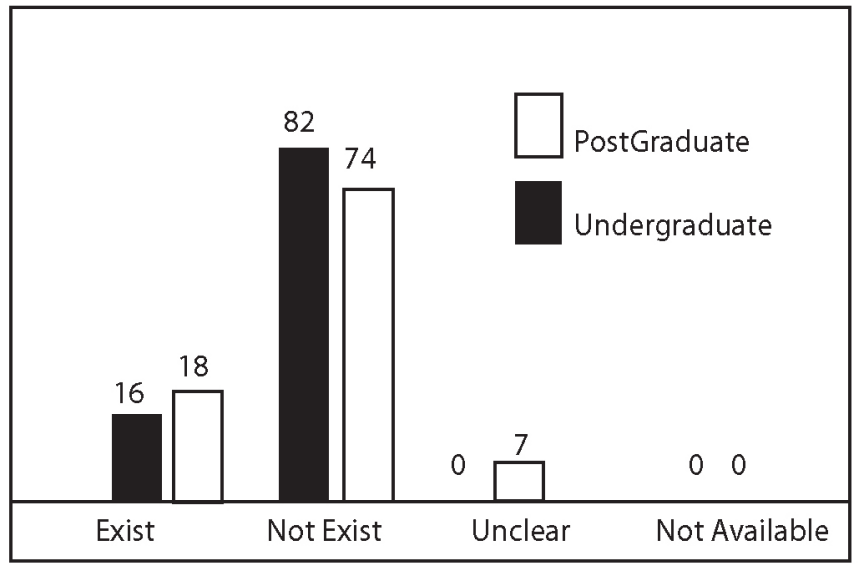

\section{Figure 6: Number of Dual-Use References}

The presence of educational content on dual-use issues was notable at undergraduate (black, $\mathrm{n}=16$ ) and postgraduate levels (white, $\mathrm{n}=18$ ).

Figure 2 showed the low level of familiarity of faculty members with the term 'dual use'. However, the quantitative results indicate that some 34 universities, of which 16 cases were in undergraduate and 18 in postgraduate courses (see Figure 6), have been providing dual-use content in their academic modules but, interestingly, without using the term itself; that is, the relationship between science and its potential misuse was a relatively common topic in existing course content at the universities surveyed.

A trend in dual-use content in existing education is illustrated by the history of science and its exploitation for violent purposes in wider fields other than the life sciences. One university had a module on Science and Society that considered what science introduced into society, including both social benefits and harmful consequences. The graduate school of the same university also had a module, Scientific Technology and Society, which reviewed the historical evolution of science and its dual-use aspects, and included illustrations of chemical and nuclear weapons. A History of Science module in another university demonstrated the

27 The second ASMeW international ethics seminar, available: http://www.waseda.jp/scoe/ sympo/080204seminar/080204e.html [viewed 17 January 2010]. 
scientific evolution from antiquity to the modern times of mass production and mass destruction. There was a further example, more specifically, Introduction to Medical Zoology, which studied a diverse range of animals and insects. Alongside its research on toxins for pharmaceutical purposes, it discussed considerations such as the many types of biotoxins that have been developed for biological weapons that can also be of concern in biocrimes.

\section{Arms-Control References}

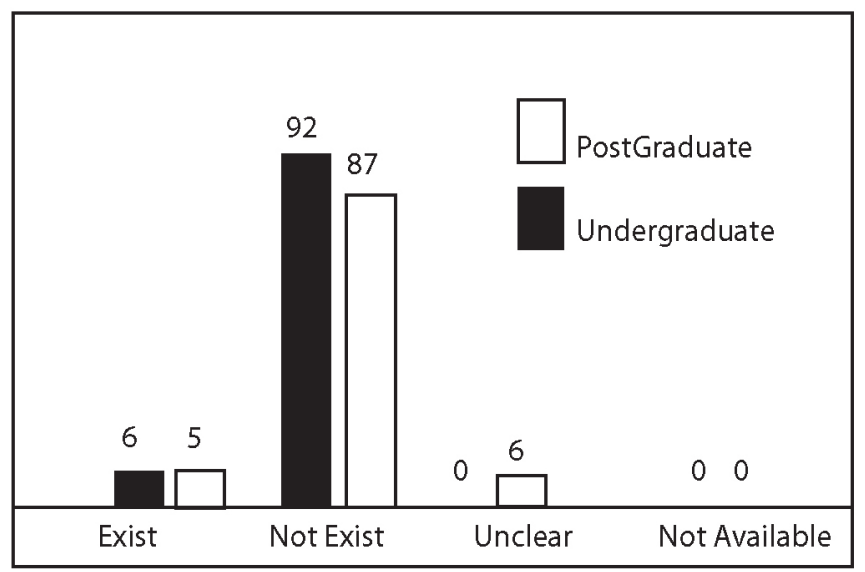

\section{Figure 7: Number of Arms-Control References}

This was the second least prevalent topic in this investigation at undergraduate (black, $n=6)$ and postgraduate levels (white, $n=5$ ).

This topic was one of the most unfamiliar themes of education found in this survey, with only 11 cases in total (see Figure 7). Unless faculty members had a specific interest in security issues, international prohibition regimes against biological and chemical weapons were not included as part of science and medical teaching. However, an undergraduate course had a forum containing a series of online papers, ${ }^{28}$ one of which provided a brief illustration of modern biowarfare programmes worldwide, with a specific focus on smallpox and anthrax. Also, the forum highlighted the potential threat of bioterrorism, using the case of Aum Shinrikyo and the anthrax attacks after 11 September in the US, to illustrate contemporary concerns over this risk. Having considered those dangers, the series moved on to cover the international prohibition against biological weapons, including the 1925 Geneva Protocol and the 1972 Biological and Toxin Weapons Convention, and what should be done in Japan to strengthen these regimes. Another module at a faculty of science entitled

28 See Research Center for Animal Life Science Shiga University of Medical Science 2008, Primate forum: Lectures on Zoonotic diseases, available: http://www.shiga-med.ac.jp/ hqanimal/ [viewed 17 January 2010]. 
Chemistry, referred to the Chemical Weapons Convention (CWC), whilst the Department of Chemistry listed the domestic laws undertaken to implement the CWC within the Department.

\section{Ethical Guidelines}

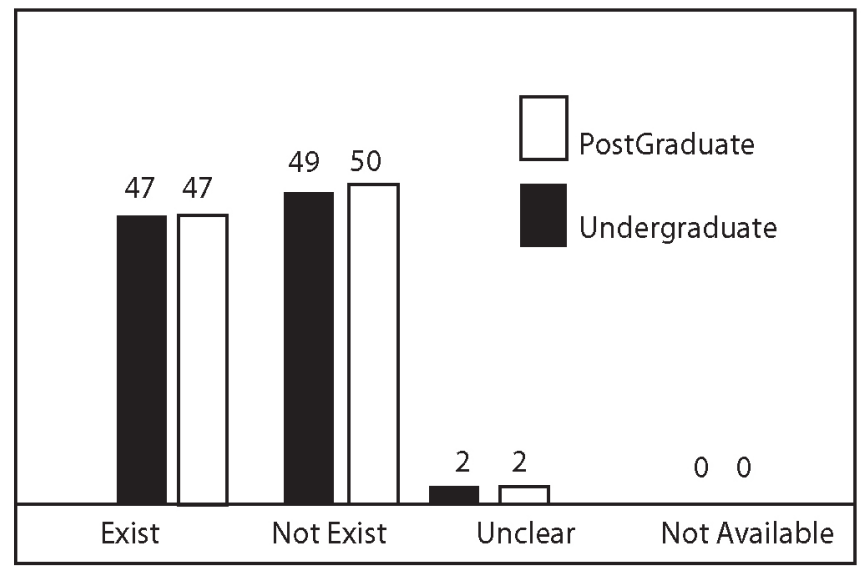

\section{Figure 8: Number of Ethical Guideline References}

Usually, being referred to within bioethics modules, this topic was widely provided at undergraduate (black, $n=47$ ) and postgraduate levels (white, $n=47$ ).

Some universities have been implementing education in this area not as full modules but with reference to relevant ethical guidelines within courses on other topics. As Figure 8 shows the references to these standards or codes of conduct for scientists have a relatively high degree of presence in our survey with 47 cases both at undergraduate and postgraduate levels. ${ }^{29}$ In addition, investigation results from the more prevalent bioethics modules could indicate a much higher presence of references to ethical guidelines or codes, because of the close overlap between both topics.

These topics are primarily provided with a view to ensuring good practice in medicine or preventing misconduct in scientific research rather than promoting understanding of dual-use issues. Most of the guidelines that could be found were in relation to research areas on the human genome, genetic engineering and human embryonic stem (ES) cells. As was the case with Living Modified Organisms (LMO) and biosafety, these have been guided by respective government regulations. However, some dual-use references could be recognised. A school of medicine noted that their university did not authorise a patent to a product of scientific research if it raised concerns regarding public safety or weapons development. Another university listed the websites of the

29 For further information, see Hara, S. and Masuda, K. 2007, 'Current state of institutional review boards (IRB) of special functioning hospitals in Japan', Clinical Evaluation, vol. 35(2), pp. 375-408. 
World Health Organisation (WHO) and the US Center for Disease Control and Prevention (CDC) with a view to providing information on biological, toxin and chemical weapons, and also references to incidents of bioterrorism with anthrax.

\section{Existing Interest in Biosecurity Education}

The survey results indicated that there was a clear lack of educational topics on biosecurity despite a certain level of presence on dual-use references. However, this does not necessarily mean there is a lack of interest in such education. In cases where there was no such module or reference at the investigated university, the questionnaire provided multiple-choice options related to each topic: 'Although we (the investigated university) have not provided such a topic: A, we should implement the topic; B, we are interested in the topic but it is difficult to implement at the own university; $\mathrm{C}$, we do not think it is necessary for our academic curricula'.

Figures 9 (undergraduate level) and 10 (postgraduate level) suggest that many universities had a positive interest in the subjects in general, especially the implementation of research guides or codes of conduct at postgraduate level. Nevertheless, the majority of the feedback also noted that it was difficult to introduce such topics in their current academic environment. The respondents also suggested there were a series of difficulties that caused the lack of provision for such education. These are elaborated in the following section.

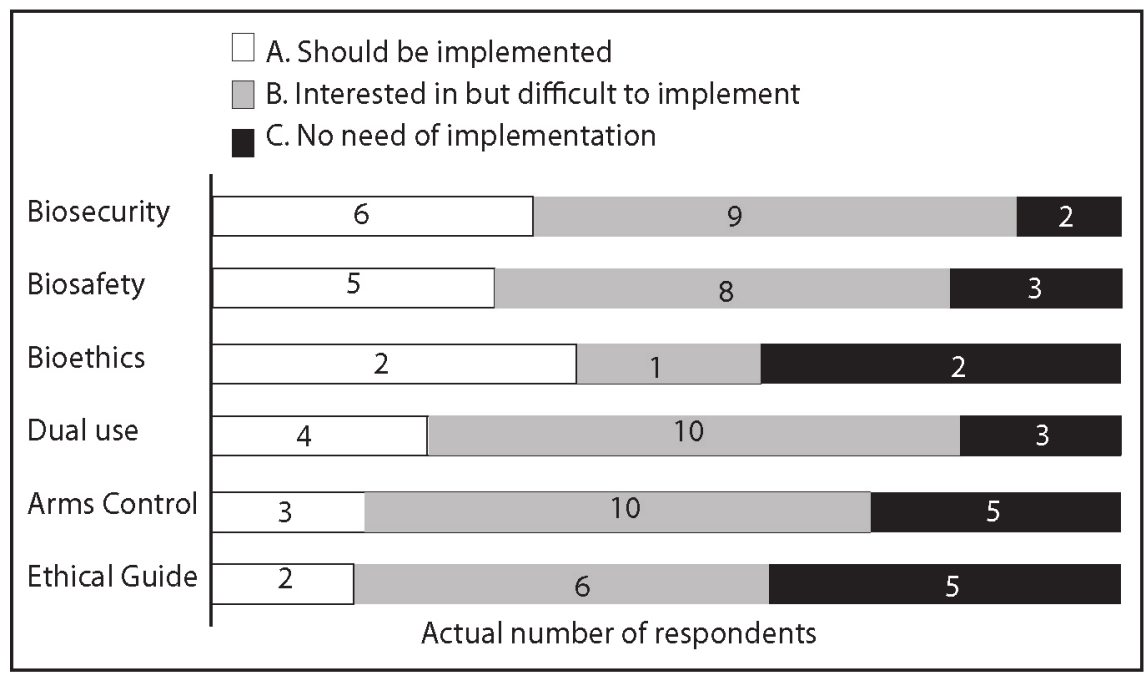

Figure 9: Interests of Faculties on Educational Topics: Undergraduate

Except for bioethics modules (gray, $n=1$ ), the majority of all other educational topics were categorised into 'B. Interested in but difficult to implement'. The interest in biosecurity modules (gray, $n=9)$ ), dual-use issues (gray, $n=10$ ) and arms control (gray, $n=10$ ) was high. Numbers on ' $C$. No need for implementation' were also notable for arms control (black, $n=5$ ) and ethical guidelines (black, $n=5$ ). 


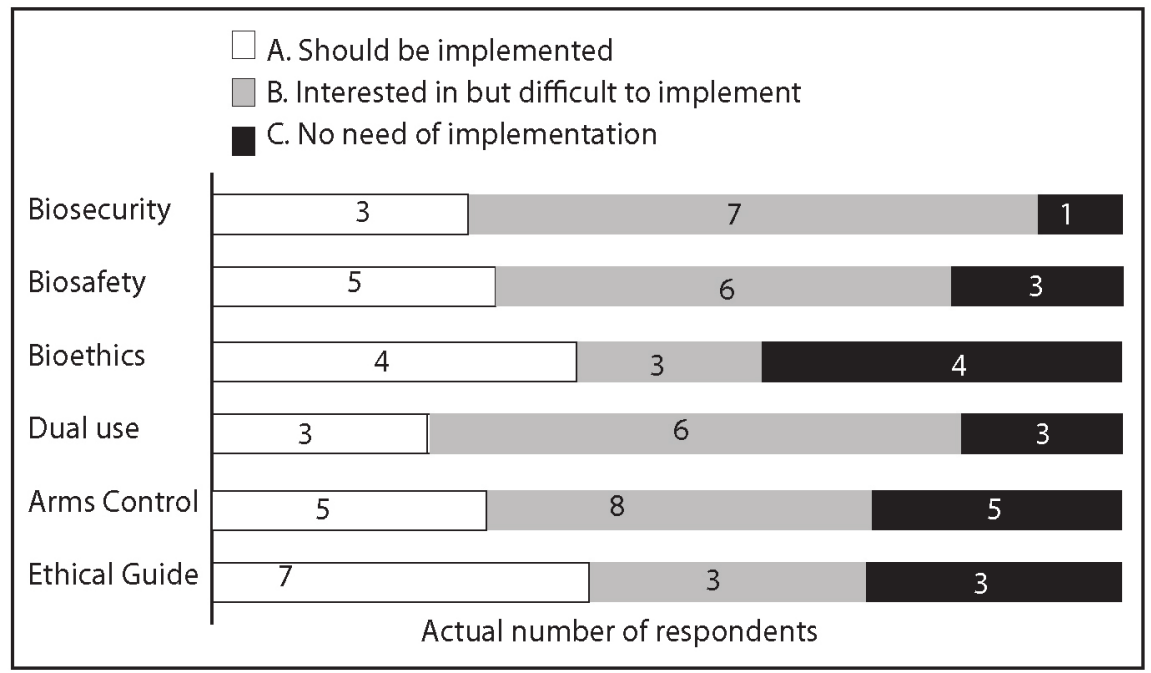

Figure 10: Interests of Faculties on Educational Topics: Postgraduate

At postgraduate level, references to ethical guidelines for research scored good interest with faculty members (white, $n=7$ ), a contrast to undergraduate level (see Figure 9). There was relatively high interest on biosecurity modules (gray, $n=9$ ), dual-use issues (gray, $n=6$ ) and arms control (gray, $n=8$ ), but the majority of answers indicated that it is difficult to implement within the current curricula.

\section{Obstacles to the Implementation of Biosecurity Education}

Although the limited number of responses from 48 departments in 24 universities does not permit a statistically significant generalised analysis, it does illustrate the difficulties faced by university lecturers. We found that the responses to our questionnaire indicated there was:

- an absence of space in the existing curricula

- an absence of time and resources to develop new curricula

- an absence of expertise and available literature on biosecurity education

- doubt about the need for biosecurity education.

\section{Dual-Use Bioethics: A Starting Point}

Despite the commonly addressed obstacles, the survey still indicates the possibility of promoting biosecurity education in Japan. Existing curricula, including courses on bioethics, would be a key intervention point for its introduction. By integrating biosecurity considerations into existing bioethics education, the ethical considerations of life scientists can be expanded to include the potential misuse of scientific knowledge. 'Dual-use bioethics' is one possible starting point to develop biosecurity education in the current Japanese educational environment. 


\section{Dual-Use Bioethics: An Additional Questionnaire}

In order to research the possibility of dual-use bioethics education, the survey team conducted an additional questionnaire by specifically targeting lecturers on bioethics education at some of the same universities. The new questionnaire asked, 'What kind of obstacles can be expected in the process to introduce dualuse issues into the existing ethical education for life scientists?' As in the earlier survey, some of the respondents identified similar uncertainties, unknowns, false starts, and doubts towards biosecurity education.

However, at the same time they addressed a certain possibility of dual-use bioethics education. One respondent noted, 'Even without a specific module on dual-use issues, introductory education for bioethics can cover dual-use issues'. Another pointed out in this regard that within the already busy curricula of universities it was of critical importance to achieve 'understanding [of the topic] and coordination amongst relevant stakeholders in the department, particularly by personnel from each research division, to develop academic administration'. To indicate how awareness of matters pertaining to dual-use bioethics could be introduced, another respondent commented that he felt that is was worthwhile and that he would 'cover the issue of dual use, including the case of Aum Shinrikyo, for about 15 minutes' in his lecture at the faculty of life science, from the following semester.

In addition to such bottom-up approaches, some top-down methods also prove useful in promoting dual-use awareness. In view of this, the additional questionnaire also asked whether ethical awareness of dual-use issues among life scientists should be used as an assessment criterion for grant applications to funding bodies, for the review processes of scientific journals, or for ranking systems of universities.

The responses to these questions varied. For example, on a positive note, one contributor noted that 'many Japanese scientists are internationally recognised with their scientific research through publication in top scientific journals, but they should also make additional efforts in order to assure the international confidence in ethical awareness of scientists about dual-use issues...and those top-down methods facilitate the latter'. Another respondent argued that 'although the establishment of such assessment criteria is necessary, raising awareness [among relevant actors involved in this evaluation process] should be a higher priority'.

This point was reinforced by other respondents, who pointed out that it would be preferable to assess the level of awareness of scientists of ethical conduct in dual-use issues and their practice to prevent the potential misuse of science. The question regarding whether awareness of such issues should be used in ranking 
universities, however, would require careful consideration. As one respondent noted, different universities 'put different emphases on science education. Some do not have faculties of science or medicine but are teaching bioethics in the social science faculties.' Whether the same standard of ethical awareness should be required within social science and natural science faculties remains a matter for further discussion.

\section{Need for an Accessible Educational Resource}

As Malcolm Dando argues elsewhere in this volume, placing open-source teaching material online, via the internet, could assist in the assimilation of biosecurity education into existing curricula, ease constraints on time spent planning and preparing material, overcome financial constraints on the development of biosecurity programmes, and provide the expertise required for efficient and effective integration of such material. ${ }^{30}$

One of the Japanese lecturers who responded to the questionnaire commented that 'comprehensive educational material is welcome, but what may be more useful would be a concise scenario-based education, backed up by audiovisual material to catch the attention of students'. The lecturer explained this is because 'many university lecturers and students in science departments may feel distant from the dual-use topics'.

By using such educational resources, a next stage to promote biosecurity teaching would be to build capacity through the implementation of such modules in different academic contexts and institutions. Knowledge gained during this process could then be used to develop best-practice standards. Specifically with regard to the second and the third stages, the following sections illustrate the experience of the NDMC.

\section{Biosecurity Education at the NDMC in 2008 and 2009}

By using a freely available online teaching resource, specifically designed for facilitating easier implementation of biosecurity education for university lecturers (that is, for 'train-the-trainers programmes' ${ }^{31}$ ) biosecurity educational agendas were provided at the NDMC in October 2008 and March 2009. ${ }^{32}$ The

30 R. 2008, 'Developing educational modules for life scientists accelerating the process though an open source initiative', presented to the IWG-LNCV Biological workshop and round table on fostering the biosecurity norm: An educational module for life sciences students, 27 October at the Municipality of Como, Italy.

31 University of Bradford 2009, Dual-use Bioethics.net, available: http://www.dual-usebioethics.net/ [viewed 17 January, 2010].

32 Minehata, M., Yamada, N., Kobayashi, Y., Shinomiya, N., Miyahira, Y., Dando, M. R. and Whitby, S. M. 2009, 'Developing an Educational Module Resource for Life Sciences through the Biological and Toxin Weapons Convention', paper presented to the 2nd Biosecurity symposium, 9-10 February Sydney, Australia. 
teaching programme in 2008 involved a five-day course for 19 postgraduate students at the beginning of their graduate degree in Medicine (see Table 2). This process was carried out using similar content for 57 medical students at the end of their six-year curriculum in 2009. These topics have now been integrated more systematically into the syllabus to raise the awareness of students.

\section{Table 2: Outline of Dual-use Education at the NDMC Graduate Course of Medicine ${ }^{33}$}

\begin{tabular}{|l|l|l|}
\hline Day & Time & Topic \\
\hline \multirow{4}{*}{ Day 1} & 09:00-09:15 & Introduction \\
\cline { 2 - 3 } & 09:15-10:45 & Life Science and Ethics \\
\cline { 2 - 3 } & $11: 00-12: 00$ & Intellectual Property \\
\hline \multirow{5}{*}{ Day 2} & $09: 00-09: 45$ & Codes of Conduct for Life Scientists \\
\cline { 2 - 3 } & $09: 45-10: 30$ & Dual-use Dilemma: History and Outline \\
\cline { 2 - 3 } & $10: 45-11: 30$ & Biological and Toxin Weapons Convention* \\
\cline { 2 - 3 } & $11: 30-12: 00$ & Present Status of Biosafety \\
\hline \multirow{5}{*}{ Day 3 } & $09: 00-09: 50$ & Biosecurity: Research Field of Concern \\
\cline { 2 - 3 } & $09: 50-10: 40$ & Surrounding Situation of Scientists and Scientific Papers \\
\cline { 2 - 3 } & $10: 50-12: 00$ & Ethics for Animal Experiments: Basic Rules and Legislations \\
\hline \multirow{2}{*}{ Day 4 } & $09: 00-10: 00$ & How to Search Scientific Papers \\
\cline { 2 - 3 } & $10: 10-11: 20$ & How to Use Statistical Analysis System (SAS) \\
\cline { 2 - 3 } & $11: 20-11: 50$ & Examination \\
\cline { 2 - 3 } & $13: 00-14: 30$ & Guidance of Core Facilities \\
\hline \multirow{5}{*}{ Day 5 } & $09: 00-10: 00$ & Feedback and Discussion 1 \\
\cline { 2 - 3 } & $10: 10-11: 20$ & Feedback and Discussion 2 \\
\cline { 2 - 3 } & $11: 20-11: 50$ & Closing Remarks \\
\hline
\end{tabular}

Note: * NDMC staff modified the online educational module resource to tailor the content into the scheduled educational time available for the course. For the online educational module resource, see University of Bradford 2009, Dual-use bioethics.net, available: http://www.dual-usebioethics.net/ [viewed 17 January 2010].

The students' understanding of the course content was tested using multiplechoice questions. The open-ended questions presented in the feedback and discussion sessions enabled students to give their views on such areas as whether they thought their own research could be a cause for concern. While some acknowledged that this could be the case, others pointed out that the awareness of scientists plays an important role in preventing possible threats, since it is difficult to verify malicious intent in life-science research. At the same

33 Source: Shinomiya, N. 2008, 'Developing the material required for mandatory dual-use education of life scientists (Part 2)', presented to the IWG - LNCV Biological workshop and round table on 'Fostering the biosecurity norm: An educational module for life sciences students', 27 October at the Municipality of Como, Italy. 
time, some argued that regulations introduced without careful consideration might harm the scientific freedom of individuals without producing effective results.

In discussing the kinds of research in the life sciences that could give rise to concern, many students referred to the Fink Committee's report on the seven categories of research areas of concern. ${ }^{34}$ Some students paid specific attention to synthetic biology. A recurring response was that synthetic biology could enable researchers to manipulate a virus's antigenicity, pathogenicity and toxicity to a great extent. Misuse of such agents makes effective prevention and response difficult. In relation to biosecurity measures, one student pointed out that 'without a host or parent virus, new viruses can be cultured based on DNA sequences and chemical synthesis...therefore, misuse cannot be prevented solely by physical control of biological agents' and would require greater governance of information and expertise.

Finally, an anonymous questionnaire was circulated to check the accessibility of each taught topic in this educational process by asking whether 'your understanding on the following aspects of the module was developed' Scoring five indicated the highest positive mark and one, the lowest. The results of the questionnaire, shown in Diagram 1, indicate that students assessed the programme very positively.

There are several lessons that can be learned from this process. Firstly, since the NDMC programmes were specifically designed for the medical students at a defence college, these programmes may not necessarily prove useful for other universities in Japan. Secondly, in light of ever-advancing life-science research, the educational content needs to be constantly updated to ensure that scientific and technological discussions about dual-use issues remain up-to-date and relevant. Furthermore, a clearer assessment framework to measure the impact of biosecurity education needs to be developed to show the value of such teaching as an academic subject.

On the positive side, the example at the NDMC demonstrates how an opensource educational module resource can be modified for specific teaching purposes in busy curricula at the university. It also shows how raising awareness is possible through lectures on essential regulations in biosecurity and letting students consider the potential dual-use consequences of their own research. It is recommended that the sharing of information among universities on experiences and lessons learned in this field should be further promoted to develop best practices in biosecurity teaching.

34 Including research on making virus resistant to a vaccine, enhancing the virulence of a pathogen or modifying the host range of a pathogen. See National Research Council 2004, Biotechnology research in an age of terrorism, Washington, DC: National Academies Press. 


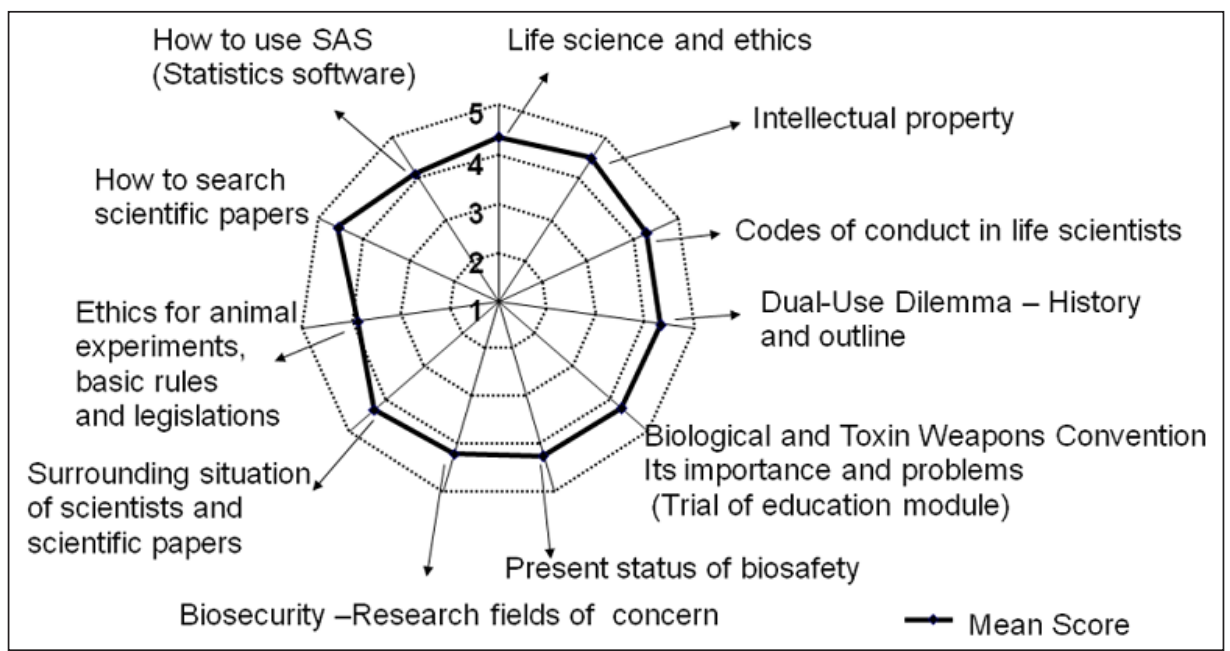

Diagram 1. Mean Score of Questionnaire by the Students on the NDMC Module $^{35}$

\section{Conclusion}

The experience of Japan indicates that university-level ethical education on dual-use issues for life scientists can be implemented successfully. The key stages of the strategy adapted in Japan included:

- surveys of existing educational courses

- contact with and among lecturers

- setting up national and international networks

- provision of assistance

- resurveys to check the implementation of education.

A focused survey is useful for investigating the current state of biosecurity teaching or educational content on dual-use issues for life scientists at institutions for higher education. At the surveyed universities, biosecurity modules, followed by arms-control and dual-use references, were the least prevalent topics within the life-science degree courses. However, universities with no biosecurity in their curricula expressed an interest in its introduction. The survey also helped reveal possible reasons why such content had been missing from existing curricula. The identification of 'uncertainties, unknowns, false starts, and doubts' can be an essential understanding prior to an effective 
policy-making process to help remove existing obstacles. The survey recognised a possible starting point of biosecurity education by integrating dual-use content into existing bioethics teaching.

A second conclusion to be drawn is that developing contact with (and among) university lecturers is important. This enables universities to share their experience of the implementation of biosecurity education to pursue best practice in such teaching. Importantly, commonly addressed obstacles by university lecturers to introduce such education seem to be structurally embedded and should be dealt with by efforts not only from individual universities, but also from government experts on security and education issues.

Thirdly, for this purpose, setting up national and international networks will be important. Through this process, the promotion of biosecurity education can accommodate the interests of practising scientists and security policymakers and make it possible to strike an appropriate balance between the freedom of scientific research and oversight of science for national security requirements. Education within scientific communities, such as domestic scientific associations and international research groups, is also a key factor to raise biosecurity awareness among life scientists.

The Research Institute of Science and Technology for Society (RISTEX) of the Japan Science and Technology Agency is an important initiative in setting up a national network of 'a few hundred stakeholders in biosecurity, including officials of all relevant ministries and agencies, and experts of universities and research institutions as well as journalists' ${ }^{36}$ This platform will play an essential role to help promote biosecurity education in Japan. Another project is an international seminar framework and a 'Safety and Secure Science \& Technology' project supported by the Ministry of Education, Culture, Sports, Science and Technology (MEXT), through which rules for preventing the malign use of science, the introduction of biosecurity/dual-use bioethics training programmes, strategies for developing secure research environment, and so on, can be discussed.

In 2006, the Science Council of Japan (SCJ) introduced a code of conduct for scientists, partly as a basis for an assessment criterion for grant applications to the Council. ${ }^{37}$ Though the code was not originally developed to promote ethical responsibility to prevent potentially dangerous consequences of dual-use life science research, ${ }^{38}$ Katsuhisa Furukawa argues that the SCJ code was 'drafted in such a way as to cover dual-use risks' as it underlines the ethical responsibility

36 Furukawa 2009, op. cit.

37 Science Council of Japan 2006, Statement: Code of conduct for scientists, available: http://www.scj.go.jp/ ja/info/kohyo/pdf/kohyo-20-s3e-1.pdf [viewed 17 January 2010].

38 Ibid. 
for the safety and security of society as well as educational programmes at research institutions. ${ }^{39}$ However, as Furukawa points out, the SCJ code has not been extended to explicitly deal with dual-use issues. ${ }^{40}$ The problem is that, to date, the academic community in Japan has paid little attention to this point and no associations for medical or life sciences are taking positive action to prevent the malign use of scientific knowledge. No Japanese scientific journals have so far introduced biosecurity review systems. Providing opportunities for life scientists to learn dual-use examples through congress seminars may solve these problems.

The provision of assistance may also include an accessible and shared education resource. The benefits of developing an open-source biosecurity education programme were demonstrated by the NDMC experience. Other possible provisions may include making ethical awareness of dual-use issues an evaluation criterion for grant applications by funding bodies or review processes for scientific journals, as well as a ranking system for universities. However, such processes require further discussion. A re-survey to analyse the implementation of education will be necessary if further provisions of assistance are provided from scientific, academic and government bodies, to facilitate the accumulation of several examples of biosecurity teaching in Japan. This process will enable the evaluation of such programmes and the sharing of knowledge of best practices of biosecurity education in Japan.

Finally, it should be noted that the series of strategic elements to implement biosecurity education in Japan would not necessarily be sufficient or available in other countries. However, Japan's experience may prove valuable to others nevertheless, whilst Japan also has much to learn from other nations. Indeed, the significance of raising awareness among life scientists should be recognised, at least amongst the member-states of the Inter-Academy Panel (IAP). ${ }^{41}$ To achieve securer advancement of the life sciences in the twenty-first century, implementation of biosecurity education and a sharing of knowledge need to be coordinated nationally and internationally, backed up by the active engagement of both scientists and other social actors.

39 See the section of codes of conduct in Furukawa 2009, op. cit.

40 Ibid.

41 Inter-Academy Panel 2005, op. cit. 